\title{
The social contagion of work avoidance goals in school and its influence on student (dis)engagement
}

\author{
Norman B. Mendoza ${ }^{1} \cdot$ Ronnel B. King ${ }^{2}$ (1) \\ Received: 1 September 2020 / Revised: 20 November 2020 / Accepted: 26 November 2020 / \\ Published online: 6 January 2021 \\ (C) Instituto Universitário de Ciências Psicológicas, Sociais e da Vida 2021
}

\begin{abstract}
Work avoidance goals, which refer to wanting to do as little as possible in school, are detrimental to school success. Given its maladaptive nature, studies have investigated the antecedents of work avoidance, such as the role of personal characteristics and socialcontextual factors. The influence of one's classmates, however, remains under-explored. Drawing from social contagion research, we examined whether work avoidance goals spread among classmates. Questionnaires were administered to 1524 adolescent students nested within 50 classes. Two waves of data were collected one semester apart. Multilevel modeling was used to analyze the data. Results showed that a student's work avoidance in Time 2 was predicted by his/her classmates' work avoidance in Time 1 . These results held even after controlling for one's own Time 1 work avoidance. Moreover, work avoidance goals led to higher levels of disengagement and lower levels of engagement. The findings demonstrate that work avoidance goals are socially contagious and that they have negative consequences for students' engagement. This study extends our theoretical understanding of work avoidance by highlighting the vital role played by one's classmates in shaping students' avoidance of schoolwork and the deleterious consequences that come with it.
\end{abstract}

Keywords Social contagion · Work avoidance goals · Avoidance goal contagion · Engagement · Disengagement

Much of the goal research in educational psychology has focused on students' goals to improve their competence (mastery goals) or to demonstrate their competence (performance goals; Dweck and Leggett 1988; Elliot and McGregor 2001; Elliot and Murayama 2008). However, there is another type of goal known as work avoidance goal, which has received less

Ronnel B. King

ronnel.king@gmail.com; ronnelking@um.edu.mo

1 Department of Curriculum and Instruction, Faculty of Education and Human Development, The Education University of Hong Kong, Hong Kong SAR, China

2 Faculty of Education, University of Macau, Macau SAR, China 
attention in the literature (Dowson and McInerney 2001; Skaalvik 1997). Work avoidance goals refer to one's desire to do as little work as possible or avoid schoolwork altogether (Dowson and McInerney 2001; Seifert and O'Keefe 2001). These goals result in less school engagement (Dowson and McInerney 2001; Fredricks et al. 2004; King 2014), suboptimal learning strategies (Somuncuoglu and Yildirim 1999), and ultimately lower academic achievement (Brdar et al. 2006; King and McInerney 2014).

Past studies have found that students' personal characteristics such as having a low need for achievement (Jagacinski et al. 2019), feeling bored at school (Jarvis and Seifert 2002), having low self-efficacy (Seifert and O'Keefe 2001), and perceiving one's intelligence as fixed rather than malleable (King and McInerney 2014) are key predictors of work avoidance goals. Aside from these personal characteristics, social-contextual factors such as one's teachers can also influence students' tendency to adopt work avoidance goals (Seifert and O'Keefe 2001; Urdan and Schoenfelder 2006). However, the role of classmates has seldom been explored. This is a crucial gap because there is a substantial body of literature showing that classmates and peers influence one's attitudes towards school and other learning-related outcomes ( $\mathrm{Li}$ et al. 2011; Urdan 1997, 2004; Wentzel et al. 2017).

Drawing on prior work on social contagion, work avoidance goals may be transmitted among students in the same class. This can predispose students with work avoidant classmates to adopt work avoidance goals themselves. To explore this possibility, we examined the social contagion of work avoidance goals and whether these goals play a role in students' engagement and disengagement in school. We adopted a longitudinal design and analyzed data from 1524 secondary school students nested in 50 classes using multilevel modeling. We tested whether classmates' work avoidance goals at Time 1 would predict one's work avoidance goals at Time 2, controlling for one's baseline work avoidance. We also explored whether and how work avoidance would predict students' engagement and disengagement.

\section{Work avoidance goals}

Work avoidance goals refer to the desire to succeed in school by doing as little as possible (Dowson and McInerney 2001; Seifert and O'Keefe 2001). It can be characterized by a dislike for homework or difficult subjects, engagement in off-task behaviors, and lack of planning as regards one's schoolwork (Dowson and McInerney 2001). Despite work avoidance goals being rooted in goal theory, work avoidance goals are distinct from the more commonly examined achievement goals, such as mastery-approach (wanting to do well relative to self-set standards) and performance-approach goals (wanting to outperform others; Elliot and Murayama 2008). While mastery-oriented students define success in terms of doing well relative to self-set standards and performance-oriented students define success in terms of outperforming their classmates, work avoidant students define success as doing the bare minimum or avoiding schoolwork entirely (Dowson and McInerney 2001, 2003). Pursuing work avoidance goals can be damaging to a student's school performance (e.g., Harackiewicz et al. 1997; King 2014).

The pursuit of work avoidance goals could lead to increased school disengagement, negative affect, and lower grades (King 2014; King and McInerney 2014), as well as lower prosocial behaviors in school (e.g., citizenship behaviors), resulting in a desire to miss or skip classes (Jagacinski et al. 2019). Work avoidant behaviors also predict lower use of deep and metacognitive learning strategies (Nolen 1988; Somuncuoglu and Yildirim 1999). It could also 
lead to a vicious cycle of an avoidance-disengagement loop (see King 2014) that could certainly hurt student achievement (e.g., Brdar et al. 2006; King and McInerney 2014).

The known antecedents of work avoidance goals include key personal and psychological characteristics. When students sense a lack of control over their learning (i.e., alienation), have a low need for achievement, and perceive that their need for competence is not being met, they are likely to pursue work avoidant goals (Jagacinski et al. 2019). Emotions like boredom and helplessness (Jarvis and Seifert 2002), as well as the lack of confidence, control, and task meaning (Seifert and O'Keefe 2001), are also key predictors of work avoidance goals. The increasing difficulty of tasks that could lead to lower perceived competence could also foster work avoidance goals (Kumar and Jagacinski 2011; see also Legault et al. 2006). However, aside from these individual-level and psychological antecedents, not much has been done to explore potential social-contextual factors that contribute to work avoidance goals, specifically, the role of peers.

\section{Social contagion}

One way through which peers could influence each other to adopt work avoidance goals is through the process of social contagion. The importance of one's classmates in school cannot be discounted as “... students' peer relationships at school are an integral feature of their learning environments" (Kindermann 2016, p. 31). How a student approaches or avoids schoolwork is anchored in his or her social environment. Because students spend most of their waking hours in school, classrooms are deemed to be "one of the most proximal and potentially powerful settings for influencing children and youth [engagement]" (Pianta et al. 2012, p. 366). A mechanism responsible for how social environments predict how one engages or, in this case, avoids schoolwork is social contagion.

Social contagion pertains to the phenomenon that the behaviors and attitudes of others can influence one's own (Christakis and Fowler 2013; Levy and Nail 1993). It posits that affect, motivation, attitudes, behaviors, and other psychological states can spread from one person to the other, even without intentional influence (see Levy and Nail 1993). As students are strongly influenced by their peers, especially during adolescence (Li et al. 2011; SimonsMorton and Chen 2009), social contagion may be pervasive in the school context. In schools, social contagion research has demonstrated that student motivational orientations (Burgess et al. 2018; Radel et al. 2010; Wild and Enzle 2002), mindsets (Burkley et al. 2017; King 2019), engagement (Mendoza and King 2020), academic achievement (Fortuin et al. 2015), and emotions (King and Datu 2017) spread among classmates. Despite the growing literature on social contagion in the educational context, whether social contagion applies to maladaptive goals like student work avoidance goals is still unknown.

\section{The social contagion of work avoidance goals}

Social contagion can operate subconsciously (Chartrand and Lakin 2013; Laurin 2016) and could influence one's goals (Custers et al. 2012); this is also known as goal contagion. Goal contagion refers to the automatic adoption and pursuit of goals inferred from others (Aarts and Dijksterhuis 2000; Aarts et al. 2004). For instance, the experiments of Bargh et al. (2001) demonstrated that merely being primed with performance-related words (e.g., strive, win) can 
activate such goals and subsequently enable actions in pursuit of such goals. Longitudinal data also suggests that achievement goals, such as mastery-approach and performance-approach goals are contagious (King and Mendoza 2020).

The early work of Levy (1992) has provided empirical explanations on the social contagion of approach-goals and avoidance-goals. In several experiments, Levy (1992) demonstrated that when an individual is deciding on whether to approach or to avoid a task, one's immediate social environment can influence such decisions. When students, for instance, see their classmates avoid schoolwork, this could prompt them to adopt the same avoidant behavior. The social contagion of avoidance is also reflected in behavioral studies. Broeren et al. (2011) found that when children are exposed to videos of their peers avoiding a novel animal, they tend to increase their fear beliefs and avoidance of the previously neutral animal. This demonstrates how avoidance behaviors could be modeled vicariously from peers. More recent experimental findings suggest that goal-directed behaviors, such as delaying or avoiding tasks, can be inferred from others' biases and influence one's behaviors, demonstrating social contagion (Devaine and Daunizeau 2017). Despite existing research on the social contagion of avoidance goals in the laboratory setting, past studies have not attempted to empirically examine whether social contagion also applies to students' work avoidance goals in the real ecologies of the classroom. This study attempts to address this gap by examining how classmates influence one's work avoidance goals in actual classroom settings, and if so, what implications does the social contagion of work avoidance goal have on student outcomes like disengagement and engagement.

\section{Disengagement and engagement}

Work avoidance goals can potentially influence how students engage and disengage with schoolwork. Student engagement and disengagement are both multidimensional constructs that can consist of behavioral, emotional, and cognitive dimensions (Archambault et al. 2009; Fredricks et al. 2004; Skinner et al. 2009; Wang et al. 2017). Broadly, engagement denotes students' involvement in school activities (Skinner et al. 2009). Engaged students have better school performance (Lee 2013), are more liklely to graduate from school (Finn 1989), and have better career trajectories after school completion (Abbott-Chapman et al. 2014) than their less engaged peers.

Conversely, disengagement refers to students' tendency to withdraw or be uninterested in schoolwork (Fredricks et al. 2004). Disengagement is not merely the opposite or the absence of engagement since it also includes the presence of maladaptive student behaviors (e.g., low effort, delinquent behaviors, substance use; Skinner et al. 2009; Wang et al. 2017; Wang and Fredricks 2014). When students are disengaged, they perform poorly in school and are at-risk for school dropout (Appleton et al. 2008; Wang and Fredricks 2014).

Longitudinal evidence suggests that work avoidance goals predict disengagement, which perpetuates further work avoidance demonstrating a vicious cycle (King 2014). Qualitative studies also highlight the link between work avoidance goals and students' decreased engagement with learning in school (Dowson and McInerney 2001). However, whether one's work avoidance goals - as potentially influenced by one's classmates - predicts one's engagement and disengagement in school is yet to be tested. Testing the social contagion of work avoidance from classmates and its impending detrimental effects on student engagement and disengagement would highlight the importance of classroom-level interventions. 


\section{The present study}

In this study, we aimed to examine the social contagion of work avoidance goals among classmates and examine whether the ensuing work avoidance goal predicts disengagement and engagement. The following hypothesis was posited:

H1: Classmates' Time 1 (T1) work avoidance will predict one's own Time 2 (T2) work avoidance (social contagion effect). Moreover, the social contagion effect will hold while accounting for one's T1 work avoidance (auto-regressor effect).

$\mathrm{H} 2$ : The T2 work avoidance goals will subsequently predict T2 behavioral and emotional disengagement.

H3: The T2 work avoidance goals will subsequently predict T2 behavioral and emotional engagement.

\section{Method}

\section{Participants}

We recruited 1524 students nested within 50 classes. Of these, 651 were males (42.7\%), and 873 were females $(57.3 \%)$. The average age was 14.73 years old $(\mathrm{SD}=1.33)$. There were 430 , Year 8, 523 Year 9, and 571 Year 10 students. The average class size was 30. All students were drawn from two public secondary schools in Metro Manila, Philippines. Both schools had similar demographic profiles and catered to lower-middle and middle-income families. In the Philippine educational system, students are assigned to the classes by the school administrators, and they attend classes with their classmates for the whole school day. Subject teachers rotated across the classes (Fig. 1).

\section{Educational context in the Philippines}

The Philippine educational system is patterned after the American educational system (Tanodra 2003). Traditionally, Filipino students undergo 6 years of elementary education

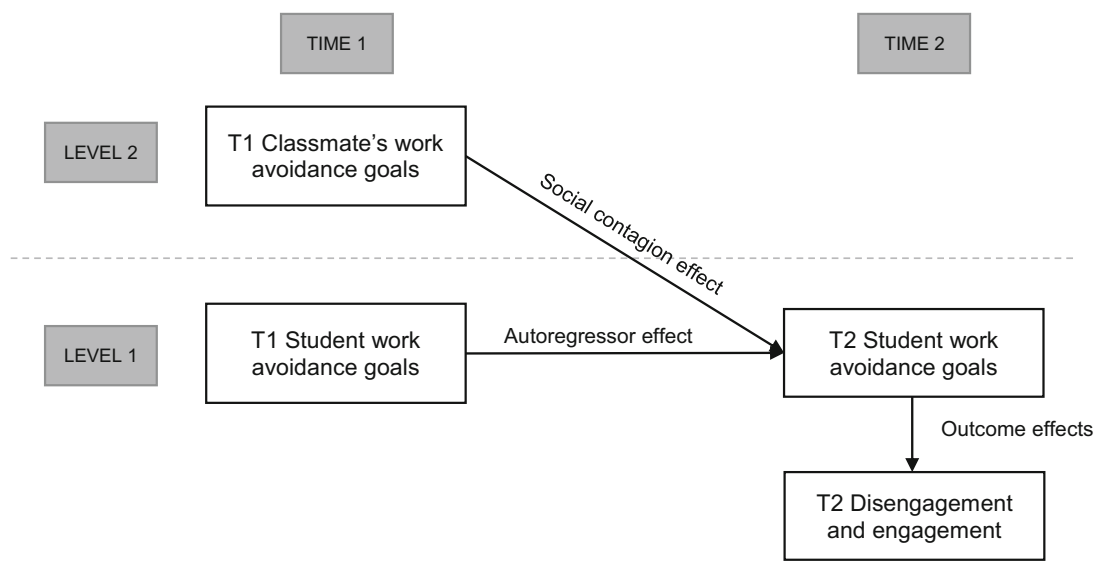

Fig. 1 Conceptual framework of the social contagion of work avoidance goals predicting student engagement and disengagement 
and 4 years of secondary school education. Recently, the government has transitioned to the K12 system (i.e., 12 years of compulsory education; Department of Education 2013; Okabe 2013). The average class size of secondary schools in the Philippines is 54 (Orleans 2007). Most recently, for the first time, the Philippines has participated in the Programme for International Student Assessment (PISA) in 2018 (OECD 2019a). Results of PISA 2018 for the Philippines highlight the suboptimal performance of students in reading, math, and science (OECD 2019b).

From a socio-cultural perspective, the Filipino indigenous core value of kapwa plays a crucial role in social relations and might have implications for contagion research. Kapwa pertains to the recognition that one shares an indistinguishable identity with others (Enriquez 1986). This awareness of a shared identity of the "self" and "others" is what builds and strengthens relatedness, social-belonging, and harmony among collectivistic societies (see David et al. 2017).

\section{Procedures}

Questionnaires were administered to the students at two time-points. The first wave of data collection took place 2 months after the school year started. The second wave of data collection occurred 7 months later. The second author administered all the questionnaires with the assistance of the class teachers during class time. Students were informed that they could withdraw from the study at any time without consequence. All invited students participated in the study.

\section{Measures}

Work avoidance goals The 6-item work avoidance subscale of the Goal Orientation and Learning Strategies Survey (GOALS-S; Dowson and McInerney 2004) was used to measure work avoidance goals. A sample item would be, "At school, I want to do as little work as possible." Items were rated on a 6-point Likert scale ( $1=$ False, not like me at all; $2=$ not like me; 3 = somewhat not like me; 4 = somewhat like me; 5 = like me; $6=$ True, very much like me). The internal reliability of the scale in Time 1 and Time 2 of the present study is $\alpha=0.81$ and $\alpha=0.88$, respectively.

Disengagement and engagement Disengagement and engagement were measured using Skinner et al.'s (2009) Engagement and Disaffection Scale. This scale has four dimensions: behavioral disengagement ( $\alpha=0.81$; "I don't try very hard at school"), emotional disengagement ( $\alpha=0.85$; "When we work on something in class, I feel bored"), behavioral engagement ( $\alpha=0.79$; "I try hard to do well in school"), and emotional engagement ( $\alpha=0.73$; "When I'm in class, I feel good."). Each subscale consists of five items, and all items were rated on a 4-point Likert scale ranging from 1 (strongly disagree) to 4 (strongly agree).

Classmate work avoidance goals To operationalize class-level work avoidance goals, we aggregated students' responses to the work avoidance goal items and used this as a between-class factor. Aggregating classmates' characteristics and using this as a between-level variable has been used in past studies that examined the role of classmate characteristics more broadly (Bifulco et al. 2011; Chiu et al. 2017; 
Persson and Svensson 2017) and social contagion more specifically (Bakker et al. 2006; King 2019; King and Datu 2017).

\section{Data analysis}

To answer the research questions, we used multi-level path analysis (i.e., means-as-outcomes regression analyses with fixed effects) in MPLUS Version 8.3 (Muthén and Muthén 19982019), which enabled us to account for the nested nature of our data. We conducted five different multilevel path models: Model 1 was the unconditional model designed to check whether multi-level path analysis is appropriate, which could be determined by checking the intra-class correlation (ICC) values. ICC refers to the proportion of total variance that is located between classes (Bliese 2000). Values of 5\% and above for ICC confirm that a variable possesses adequate class-level properties that warrant the use of multi-level modeling (Gavin and Hofmann 2002).

Model 2 was the social contagion model that tested whether classmates' work avoidance goals at Time 1 predicted Time 2 work avoidance goals. We included one's work avoidance goal at Time 1 to account for students' baseline (i.e., autoregressor effects). Autoregressor effects pertain to "the effect of a construct on itself measured at a later time" (Selig and Little 2012, p. 265). Models 3 to 6 tested whether work avoidance contagion has implications for students' subsequent levels of behavioral disengagement, emotional disengagement, behavioral engagement, and emotional engagement, respectively.

We used the following goodness-of-fit indices to evaluate all models: Comparative Fit Index (CFI), Tucker-Lewis Index (TLI), Root Mean Square Error of Approximation (RMSEA), and standardized root mean square residual (SRMR). Following Hu and Bentler's (1995) recommendation, a good model fit would include a model CFI and TLI of greater than 0.90 and an RMSEA of less than .08 (see also Steiger 1990). An SRMR value less than .08 is considered as good fit, and .00 is a perfect fit $(\mathrm{Hu}$ and Bentler 1999). The $p$ value of the $\chi^{2}$ should be greater than 0.05 , but with larger sample sizes, a $p$ value greater than 0.05 may still indicate good model fit (see Barrett 2007).

Note that rather than putting all the study variables together in one overall multilevel model, we tested the effects of work avoidance goals on the disengagement and engagement dimensions in separate models. The reason for this was because the number of level 2 units (50 classes) was on the lower end of the recommended threshold for multi-level models (Meuleman and Billiet 2009). Putting all the variables together in one overall model is not advisable, given the small number of level 2 units, which might lead to an overfitted model.

\section{Results}

Descriptive statistics and internal reliability estimates are shown in Table 1. All scales had adequate internal consistency. Below we present six models in testing the research hypotheses: 
Table 1 Bivariate correlations, descriptive statistics, and Cronbach's alpha

\begin{tabular}{|c|c|c|c|c|c|c|}
\hline & 1 & 2 & 3 & 4 & 5 & 6 \\
\hline 1.T1 work avoidance & & $.425^{* * *}$ & $.298^{* * * *}$ & $.271^{* * *}$ & $-.155^{* * *}$ & $-.154^{* * *}$ \\
\hline 2.T2 work avoidance & & & $.443^{* * *}$ & $.419^{* * * *}$ & $-.175^{* * *}$ & $-.159^{* * * *}$ \\
\hline 3.T2 behavioral disengagement & & & & $.781^{* * * *}$ & $-.271^{* * *}$ & $-.198^{* * * *}$ \\
\hline 4.T2 emotional disengagement & & & & & $-.232^{* * * *}$ & $-.292^{* * *}$ \\
\hline 5. T2 behavioral engagement & & & & & & $.728^{* * * *}$ \\
\hline \multicolumn{7}{|l|}{ 6.T2 emotional engagement } \\
\hline Mean & 2.99 & 3.23 & 2.16 & 1.96 & 3.21 & 3.22 \\
\hline $\mathrm{SD}$ & 1.04 & 1.08 & .55 & .53 & .47 & .44 \\
\hline Cronbach's alpha & .81 & .88 & .81 & .85 & .79 & .73 \\
\hline Skewness & .23 & .18 & -.09 & .30 & -.42 & -.32 \\
\hline Kurtosis & -.31 & -.39 & -.05 & .17 & 1.01 & 1.34 \\
\hline
\end{tabular}

Note: $* * * p<.001$

\section{Model 1: unconditional model}

We first tested an unconditional model with the T2 work avoidance goal as the outcome. The ICC was 0.102 , indicating that $10.2 \%$ of the variance in T2 work avoidance was between classes. The intercept variance between classes was .119, while that within classes was 1.048.

\section{Model 2: social contagion of work avoidance}

We tested our work avoidance goal contagion hypothesis by examining a two-level regression model where classmates' T1 work avoidance goal at the between class-level were used as a predictor of $\mathrm{T} 2$ work avoidance goals. We also took auto-regressors into account by using one's T1 work avoidance as a predictor of subsequent work avoidance at the within level. Results confirmed our work avoidance goal hypothesis. T1 work avoidance predicted T2 work avoidance at the between class-level $(\beta=.733, p<.001)$ despite taking into account autoregressor effects $(\beta=.406, p<.001)$. As a result of adding predictors at the between and within-class levels, the variance between classes decreased to .055 , while that within-classes decreased to .875 .

\section{Model 3: work avoidance goal predicting behavioral disengagement}

We tested Model 3, which involved testing a model wherein T1 work avoidance predicted T2 work avoidance, which in turn predicted T2 behavioral disengagement. Results indicated a good fit to the data: $\left(\chi^{2}(2)=30.11 ; p<.01 ; \mathrm{CFI}=.96 ; \mathrm{TLI}=.86\right.$; RMSEA $=.096$; $\mathrm{SRMR}_{(\text {within) }}=.053 ; \mathrm{SRMR}_{(\text {between })}=.038$. Though most of the model fit indices were adequate, the RMSEA value suggests marginal fit (see Steiger 1990). However, more recent studies indicate that multiple model fit parameters should be taken into account in evaluating model fit and not just RMSEA (Marsh et al. 2005; Marsh et al. 2004). Model 3 still has a good overall model fit as the CFI, TLI, and SRMR all had acceptable fit values (Hu and Bentler 1995, 1999).

At the between-level, T1 classmates' work avoidance positively predicted T2 work avoidance $\left(\beta=.726, p<.001 ; R^{2}=52.6 \%\right)$, which in turn predicted behavioral disengagement $(\beta=.960$, $\left.p<.001 ; R^{2}=92.2 \%\right)$. The indirect effect of T1 classmates' work avoidance on T2 behavioral disengagement was statistically significant $(\beta=.697 ; \mathrm{SE}=.130 ; Z=5.369, p<.001)$. 
At the individual level, the same pattern was replicated. T1 work-avoidance predicted T2 work avoidance $\left(\beta=.407, p<.001 ; R^{2}=16.6 \%\right)$ which then predicted T2 behavioral disengagement $\left(\beta=.398, p<.001 ; R^{2}=15.9 \%\right)$. The indirect effect of T1 classmates' work avoidance on $\mathrm{T} 2$ behavioral disengagement was statistically significant $(\beta=.162 ; \mathrm{SE}=.013 ; Z=$ $12.572, p<.001)$.

\section{Model 4: work avoidance predicting emotional disengagement}

Model 4 involved testing the role of work avoidance goals and work avoidance contagion in predicting emotional disengagement. Results indicated a good fit to the data: $\left(\chi^{2}(2)=30.11\right.$; $p<.01 ; \mathrm{CFI}=.97 ; \mathrm{TLI}=.90 ; \mathrm{RMSEA}=.086 ; \mathrm{SRMR}_{\text {(within) }}=.053 ; \mathrm{SRMR}_{\text {(between) }}=.038$. The RMSEA is also slightly higher than the recommended .08 threshold (Steiger 1990), but all the other fit indices were acceptable (Hu and Bentler 1995, 1999). At the between-level, T1 classmates' work avoidance positively predicted T2 work avoidance $\left(\beta=.726, p<.001 ; R^{2}=\right.$ $52.6 \%)$, which in turn predicted behavioral disengagement $\left(\beta=.960, p<.001 ; R^{2}=92.2 \%\right)$. The indirect effect of T1 classmates' work avoidance on T2 behavioral disengagement was statistically significant $(\beta=.697 ; \mathrm{SE}=.130 ; Z=5.369, p<.001)$.

At the individual level, the same pattern of results was replicated. T1 work-avoidance predicted T2 work avoidance $\left(\beta=.407, p<.001 ; R^{2}=16.6 \%\right)$ which then predicted T2 behavioral disengagement $\left(\beta=.398, p<.001 ; R^{2}=15.9 \%\right)$. The indirect effect of T1 classmates' work avoidance on T2 behavioral disengagement was statistically significant $(\beta=.162$; $\mathrm{SE}=.013 ; Z=12.572, p<.001)$.

\section{Model 5: work avoidance predicting behavioral engagement}

Model 5 involved testing the role of work avoidance goals and work avoidance contagion in predicting emotional disengagement. Results indicated a good fit to the data: $\left(\chi^{2}(2)=12.517\right.$; $p<.01 ; \mathrm{CFI}=.97 ; \mathrm{TLI}=.91 ; \mathrm{RMSEA}=.059 ; \mathrm{SRMR}_{\text {(within) }}=.033 ; \mathrm{SRMR}_{\text {(between) }}=.100$. At the between-level, T1 classmates' work avoidance positively predicted T2 work avoidance $\left(\beta=.726, p<.001 ; R^{2}=52.8 \%\right)$. However, T2 work avoidance was not a significant predictor of behavioral disengagement $\left(\beta=-.033, p<.001 ; R^{2}=0 \%\right)$.

At the individual level, T1 work-avoidance predicted T2 work avoidance $(\beta=.407$, $\left.p<.001 ; R^{2}=16.5 \%\right)$ which then predicted T2 behavioral disengagement $(\beta=-.184$, $\left.p<.001 ; R^{2}=3.4 \%\right)$. The indirect effect of T1 classmates' work avoidance on $\mathrm{T} 2$ behavioral disengagement was statistically significant $(\beta=-.075 ; \mathrm{SE}=.011 ; Z=-6.736, p<.001)$.

\section{Model 6: work avoidance predicting emotional engagement}

Model 6 involved testing the role of work avoidance goals and work avoidance contagion in predicting emotional engagement. Results indicated a good fit to the data: $\left(\chi^{2}(2)=13.595\right.$; $p<.01 ; \mathrm{CFI}=.97 ; \mathrm{TLI}=.90 ; \mathrm{RMSEA}=.062 ; \mathrm{SRMR}_{\text {(within) }}=.035 ; \mathrm{SRMR}_{\text {(between) }}=.085$. At the between-level, T1 classmates' work avoidance positively predicted T2 work avoidance $\left(\beta=.740, p<.001 ; R^{2}=54.8 \%\right)$. However, T2 work avoidance was not a significant predictor of behavioral disengagement $\left(\beta=-.452, p<.05 ; R^{2}=20.4 \%\right)$. The indirect effect of $\mathrm{T} 1$ classmates' work avoidance on T2 emotional engagement was statistically significant $(\beta=$ $-.330 ; \mathrm{SE}=.151 ; Z=-2.179, p<.001)$. 
At the within level, T1 work-avoidance predicted T2 work avoidance $(\beta=.406, p<.001$; $\left.R^{2}=16.5 \%\right)$ which then predicted T2 behavioral disengagement $\left(\beta=-.140, p<.001 ; R^{2}=\right.$ $2 \%)$. The indirect effect of T1 classmates' work avoidance on T2 behavioral disengagement was statistically significant $(\beta=-.057 ; \mathrm{SE}=.011 ; Z=-5.218, p<.001)$.

\section{Discussion}

This study was designed to investigate whether work avoidance goals spread among classmates. The findings indicated that classmates' work avoidance at Time 1 predicted student work avoidance at Time 2, demonstrating support for H1 (social contagion effect). This finding held even after controlling for students' Time 1 work avoidance goals. We also found support for H2 and H3 in that T1 classmates' work avoidance goals predicted T2 work avoidance, which, in turn, positively predicted disengagement $(\mathrm{H} 2)$ and negatively predicted engagement (H3).

Our findings extend the theoretical literature on social contagion to the domain of work avoidance goals. Previous studies on work avoidance goals have mostly focused on personal (Dowson and McInerney 2001; Jagacinski et al. 2019; Jarvis and Seifert 2002; King 2014; King and McInerney 2014) and teacher-related factors (Seifert \& O'Keefe, 2001; Urdan and Schoenfelder 2006). As a goal construct that has received relatively less research attention, the current findings provide evidence that classmates' work avoidance goals can amplify one's work avoidance goals, which would, in turn, is associated with disengagement from school.

Our findings support the study of Devaine and Daunizeau (2017), which showed that task disengagement could be inferred from others. Converging with past experimental studies (e.g., Broeren et al. 2011), we found that avoidance can be modeled from proximal peers. In this case, we found that students can infer and model work avoidance goals from their classmates. Indeed, aside from the social and psychological environment that teachers create (Ames 1992; Dweck and Leggett 1988; King and McInerney 2014; Seifert 1997), peers can also influence the avoidance of schoolwork. While students' sense of incompetence, lack of control, or lack of task-meaning are predictors of work avoidance (Seifert and O'Keefe 2001), one's classmates can also shape one's work avoidance goal pursuits.

The theoretical mechanisms behind the contagion of work avoidance goals can be explained by behavioral, psychological, and socio-cultural processes. Work avoidance goals can be contagious in the classroom due to observational or vicarious learning (Hatfield et al. 2009; see also Broeren et al. 2011). If people unconsciously mimic various emotions or behaviors from those around them (Hatfield et al. 2009; B. Wild et al. 2001), it is also possible for students to imitate their classmates' work avoidance goals. Exposure to emotions and attitudes toward tasks often ripples to one's own behaviors (e.g., Barsade 2002), which could also explain the spread of work avoidance goals. Hence, merely seeing or observing other students avoid their schoolwork can trigger the same goal in oneself by way of mimicry.

From a psychological perspective, a more specific type of social contagion called "disinhibitory contagion" can also shed light on how work avoidance goals are transmitted. Disinhibitory contagion (Levy 1992) explains how a person who has an approach-avoidance conflict (e.g., unsure whether to do schoolwork or not) can be freed from such conflict as a result of observing the decision of others (see also Levy and Nail 1993). While similar to conformity, disinhibitory contagion is different as it begins with an internal conflict followed by the influence of the social environment to conform (Nail et al. 2000), whereas conformity 
may not include the element of internal conflict. Given that work avoidance goals are not normative, students may feel a sense of doubt or dissonance before pursuing work avoidance goals. However, while in a current state of internal conflict as to whether to pursue a task or not, the presence of others who are already avoiding schoolwork can influence one to adopt the same detrimental goal. In short, when a student contemplates whether to tackle a task or not, observing one's classmates defer or avoid tasks can facilitate the pursuit of work avoidance.

Considering socio-cultural elements, the process of group polarization and cultural values can also play a role in work avoidance contagion. Group polarization pertains to the tendency for a group to create a stronger response tendency or behavior after members interact with each other (McGarty et al. 1992). This means that when students interact with their classmates who pursue work avoidance goals, their own tendency to engage in work avoidance could magnify. This could also be further enhanced by the psychological core value of oneness (i.e., kapwa) among Filipinos, which emphasizes social harmony and the need to fit in with others (Enriquez 1986). There is the possibility that students who see their classmates pursuing work avoidance goals might also be more likely to pursue the same goal in order to fit in with their social group (Bond and Smith 1996).

Finally, our findings suggest the cascading effect of socially contagious work avoidance goals on student engagement and disengagement in school. This adds to the growing literature on work avoidance goals (e.g., Dowson and McInerney 2001; King 2014; King and McInerney 2014) by broadening the perspective from personal factors to social and contextual factors such as classmates. Understanding that work avoidance goals inferred from classmates can make one less engaged underscores the importance of early and effective classroom interventions. Engagement and disengagement are core pillars of student achievement and motivation (Skinner et al. 2008; Wang et al. 2017); hence, factors that influence both should be given due attention.

Our findings demonstrate how a student's proximal learning environment influences one's own work avoidance goal. This finding opens up potential areas of intervention on a classroom-level. Traditionally, when a student exhibits work avoidant behaviors, the tendency might be to put the onus on the student and to design interventions at the individual level. However, our work suggests that classmates may play an essential role in this process. Hence, interventions may also need to target the social environment, particularly one's peers. Mitigating the harmful effects of student work avoidance goals is crucial because if left neglected, work avoidance could lead to maladaptive school outcomes.

\section{Study limitations and areas for future research}

Despite the strengths of our study, we noted some study limitations to draw due caution in interpreting the study findings. First, although our finding was able to demonstrate the social contagion of work avoidance goals using the aggregate work avoidance scores of the class, a more precise analysis of ties and networks can provide more nuance to these results. Future work can benefit from collecting information on whom students spend the most time with and examining these ties using social network analysis. Second, we did not collect and hence cannot control teacher-related variables in our study. Teachers are also critical social agents and may play a role in whether and how work avoidance goals are transmitted among their students. Future studies can collect teacher-relevant data to control for such factors. Third, our study is limited by an over-reliance on self-reported data. Teacher-reported data on students' work avoidance goals or having more objective measures of engagement (e.g., progress reports) can strengthen the study findings. Finally, our study only focused on work avoidance 
goal, a maladaptive type of goal. Future research can consider investigating more positive school constructs (e.g., self-efficacy, intrinsic motivation, growth mindset, engagement), and how such constructs could also be influenced by social contagion processes.

\section{Conclusion}

Classmate's work avoidance goals can influence one's own work avoidance goals. This study highlights the importance of social contagion in explaining why students pursue work avoidance goals and the deleterious consequences of doing so. To broaden our understanding of maladaptive motivations in school, researchers may need to be more attentive to the potential role of social contagion among classmates and what implications this might have in shaping students' learning and engagement.

\section{References}

Aarts, H., \& Dijksterhuis, A. (2000). Habits as knowledge structures: automaticity in goal-directed behavior. Journal of Personality and Social Psychology, 78(1), 53-63. https://doi.org/10.1037/0022-3514.78.1.53.

Aarts, H., Gollwitzer, P. M., \& Hassin, R. R. (2004). Goal contagion: perceiving is for pursuing. Journal of Personality and Social Psychology, 87(1), 23-37. https://doi.org/10.1037/0022-3514.87.1.23.

Abbott-Chapman, J., Martin, K., Ollington, N., Venn, A., Dwyer, T., \& Gall, S. (2014). The longitudinal association of childhood school engagement with adult educational and occupational achievement: findings from an australian national study. British Educational Research Journal, 40(1), 102-120. https://doi.org/10. 1002/berj.3031.

Ames, C. (1992). Classrooms: goals, structures, and student motivation. Journal of Educational Psychology, 84(3), 261-271. https://doi.org/10.1037/0022-0663.84.3.261.

Appleton, J. J., Christenson, S. L., \& Furlong, M. J. (2008). Student engagement with school: critical conceptual and methodological issues of the construct. Psychology in the Schools, 45(5), 369-386. https://doi.org/10. 1002/pits.20303.

Archambault, I., Janosz, M., Morizot, J., \& Pagani, L. (2009). Adolescent behavioral, affective, and cognitive engagement in school: relationship to dropout. Journal of School Health, 79(9), 408-415. https://doi.org/10. 1111/j.1746-1561.2009.00428.x.

Bakker, A. B., Emmerik, H. v., \& Euwema, M. C. (2006). Crossover of burnout and engagement in work teams. Work and Occupations, 33(4), 464-489. https://doi.org/10.1177/0730888406291310.

Bargh, J. A., Gollwitzer, P. M., Lee-Chai, A., Barndollar, K., \& Trotschel, R. (2001). The automated will: nonconscious activation and pursuit of behavioral goals. Journal of Personality and Social Psychology, 81(6), 1014-1027. https://doi.org/10.1037/0022-3514.81.6.1014.

Barrett, P. (2007). Structural equation modelling: adjudging model fit. Personality and Individual Differences, 42(5), 815-824. https://doi.org/10.1016/j.paid.2006.09.018.

Barsade, S. G. (2002). The ripple effect: emotional contagion and its influence on group behavior. Administrative Science Quarterly, 47(4), 644-675. https://doi.org/10.2307/3094912.

Bifulco, R., Fletcher, J. M., \& Ross, S. L. (2011). The effect of classmate characteristics on post-secondary outcomes: evidence from the add health. American Economic Journal: Economic Policy, 3(1), $25-53$. https://doi.org/10.1257/pol.3.1.25.

Bliese, P. D. (2000). Within-group agreement, non-independence, and reliability: implications for data aggregation and analysis. In Multilevel theory, research, and methods in organizations: Foundations, extensions, and new directions (pp. 349-381). San Francisco, CA, US: Jossey-Bass.

Bond, R., \& Smith, P. B. (1996). Culture and conformity: a meta-analysis of studies using asch's (1952b, 1956) line judgment task. Psychological Bulletin, 119(1), 111-137. https://doi.org/10.1037/0033-2909.119.1.111.

Brdar, I., Rijavec, M., \& Loncaric, D. (2006). Goal orientations, coping with school failure and school achievement. European Journal of Psychology of Education, 21(1), 53-70. https://doi.org/10.1007/Bf03173569.

Broeren, S., Lester, K. J., Muris, P., \& Field, A. P. (2011). They are afraid of the animal, so therefore i am too: influence of peer modeling on fear beliefs and approach-avoidance behaviors towards animals in typically developing children. Behaviour Research and Therapy, 49(1), 50-57. https://doi.org/10.1016/j.brat.2010.11.001. 
Burgess, L. G., Riddell, P. M., Fancourt, A., \& Murayama, K. (2018). The influence of social contagion within education: a motivational perspective. Mind Brain and Education, 12(4), 164-174. https://doi.org/10.1111/ mbe. 12178 .

Burkley, E., Curtis, J., \& Hatvany, T. (2017). The social contagion of incremental and entity trait beliefs. Personality and Individual Differences, 108, 45-49. https://doi.org/10.1016/j.paid.2016.11.063.

Chartrand, T. L., \& Lakin, J. L. (2013). The antecedents and consequences of human behavioral mimicry. Annual Review of Psychology, 64(1), 285-308. https://doi.org/10.1146/annurev-psych-113011-143754.

Chiu, M. M., Chow, B. W.-Y., \& Joh, S. W. (2017). Streaming, tracking and reading achievement: a multilevel analysis of students in 40 countries. Journal of Educational Psychology, 109(7), 915-934. https://doi.org/10. 1037/edu0000188.

Christakis, N. A., \& Fowler, J. H. (2013). Social contagion theory: examining dynamic social networks and human behavior. Statistics in Medicine, 32(4), 556-577. https://doi.org/10.1002/sim.5408.

Custers, R., Eitam, B., \& Bargh, J. A. (2012). Conscious and unconscious processes in goal pursuit. In H. Aarts \& A. J. Elliot (Eds.), Goal-directed behavior (pp. 231-266). New York, NY, US: Psychology Press.

David, E., Sharma, D. K. B., \& Petalio, J. (2017). Losing kapwa: colonial legacies and the filipino american family. Asian American Journal of Psychology, 8(1), 43-55.

Department of Education. (2013). Implementing rules and regulations (irr) of republic act no. 10533 otherwise known as the enhanced basic education act of 2013 (deped order no. 43, s. 2013). Pasig city, Manila: Author Retrieved from https://www.deped.gov.ph/wp-content/uploads/2013/09/DO_s2013 43.pdf. Accessed 21 Nov 2020.

Devaine, M., \& Daunizeau, J. (2017). Learning about and from others' prudence, impatience or laziness: The computational bases of attitude alignment. PLoS Computational Biology, 13(3), e1005422. https://doi.org/ 10.1371/journal.pcbi.1005422.

Dowson, M., \& McInerney, D. M. (2001). Psychological parameters of students' social and work avoidance goals: a qualitative investigation. Journal of Educational Psychology, 93(1), 35-42. https://doi.org/10.1037// 0022-0663.93.1.35.

Dowson, M., \& McInerney, D. M. (2003). What do students say about their motivational goals?: towards a more complex and dynamic perspective on student motivation. Contemporary Educational Psychology, 28(1), 91-113. https://doi.org/10.1016/S0361-476X(02)00010-3.

Dowson, M., \& McInerney, D. M. (2004). The development and validation of the goal orientation and learning strategies survey (goals-s). Educational and Psychological Measurement, 64(2), 290-310. https://doi.org/10. $1177 / 0013164403251335$.

Dweck, C. S., \& Leggett, E. L. (1988). A social-cognitive approach to motivation and personality. Psychological Review, 95(2), 256-273. https://doi.org/10.1037/0033-295x.95.2.256.

Elliot, A. J., \& McGregor, H. A. (2001). A 2 x 2 achievement goal framework. Journal of Personality and Social Psychology, 80(3), 501-519. https://doi.org/10.1037/0022-3514.80.3.501.

Elliot, A. J., \& Murayama, K. (2008). On the measurement of achievement goals: critique, illustration, and application. Journal of Educational Psychology, 100(3), 613-628. https://doi.org/10.1037/0022-0663.100.3. 613.

Enriquez, V. G. (1986). Kapwa: A core concept in Filipino social psychology. In V. G. Enriquez (Ed.), Philippine world view (pp. 6-19). Singapore: Institute of Southeast Asian Studies.

Finn, J. D. (1989). Withdrawing from school. Review of Educational Research, 59(2), 117-142.

Fortuin, J., Geel, M. v., \& Vedder, P. (2015). Peers and academic achievement: a longitudinal study on selection and socialization effects of in-class friends. The Journal of Educational Research, 109(1), 1-6. https://oi. org/10.1080/00220671.2014.917257.

Fredricks, J. A., Blumenfeld, P. C., \& Paris, A. H. (2004). School engagement: potential of the concept, state of the evidence. Review of Educational Research, 74(1), 59-109. https://doi.org/10.3102/00346543074001059.

Gavin, M. B., \& Hofmann, D. A. (2002). Using hierarchical linear modeling to investigate the moderating influence of leadership climate. The Leadership Quarterly, 13(1), 15-33. https://doi.org/10.1016/S10489843(01)00102-3.

Harackiewicz, J. M., Barron, K. E., Carter, S. M., Lehto, A. T., \& Elliot, A. J. (1997). Predictors and consequences of achievement goals in the college classroom: maintaining interest and making the grade. Journal of Personality and Social Psychology, 73(6), 1284-1295. https://doi.org/10.1037/0022-3514.73.6. 1284.

Hatfield, E., Rapson, R. L., \& Yen-Chi, L. L. (2009). Emotional contagion and empathy. In J. Decety \& W. Ickes (Eds.), The social neuroscience of empathy. Cambridge, Massachusetts: The MIT Press.

Hu, L. T., \& Bentler, P. M. (1995). Evaluating model fit. In Structural equation modeling: Concepts, issues, and applications (pp. 76-99). Thousand Oaks, CA, US: Sage Publications, Inc.. 
Hu, L. T., \& Bentler, P. M. (1999). Cutoff criteria for fit indexes in covariance structure analysis: conventional criteria versus new alternatives. Structural Equation Modeling: A Multidisciplinary Journal, 6(1), 1-55. https://doi.org/10.1080/10705519909540118.

Jagacinski, C. M., Kumar, S., \& Keith, M. G. (2019). Expanding the nomological network of work avoidance: antecedents and consequences across contexts. The Journal of Experimental Education, 88(2), 221-244. https://doi.org/10.1080/00220973.2019.1635564.

Jarvis, S., \& Seifert, T. L. (2002). Work avoidance as a manifestation of hostility, helplessness, and boredom. Alberta Journal of Educational Research, 48(2), 174-187.

Kindermann, T. A. (2016). Peer group influences on students' academic motivation. In Handbook of social influences in school contexts: Social-emotional, motivation, and cognitive outcomes (pp. 31-47). Wentzel, Kathryn R. Ramani, Geetha B.: Routledge.

King, R. B. (2014). The dark cycle of work avoidance goals and disengagement: a cross-lagged analysis. Psychological Studies, 59(3), 268-277. https://doi.org/10.1007/s12646-014-0267-5.

King, R. B. (2019). Mindsets are contagious: the social contagion of implicit theories of intelligence among classmates. British Journal of Educational Psychology, 0(0), 90(2), 349-363. https://doi.org/10.1111/bjep. 12285.

King, R. B., \& Datu, J. A. (2017). Happy classes make happy students: classmates' well-being predicts individual student well-being. Journal of School Psychology, 65, 116-128. https://doi.org/10.1016/j.jsp.2017.07.004.

King, R. B., \& McInerney, D. M. (2014). The work avoidance goal construct: examining its structure, antecedents, and consequences. Contemporary Educational Psychology, 39(1), 42-58. https://doi.org/10. 1016/j.cedpsych.2013.12.002.

King, R. B., \& Mendoza, N. B. (2020). Achievement goal contagion: mastery and performance goals spread among classmates. Social Psychology of Education, 23(3), 795-814. https://doi.org/10.1007/s11218-02009559-x.

Kumar, S., \& Jagacinski, C. M. (2011). Confronting task difficulty in ego involvement: change in performance goals. Journal of Educational Psychology, 103(3), 664-682. https://doi.org/10.1037/a0023336.

Laurin, K. (2016). Interpersonal influences on goals: current and future directions for goal contagion research. Social and Personality Psychology Compass, 10(11), 668-678. https://doi.org/10.1111/ $\operatorname{spc} 3.12289$.

Lee, J.-S. (2013). The relationship between student engagement and academic performance: is it a myth or reality? The Journal of Educational Research, 107(3), 177-185. https://doi.org/10.1080/00220671.2013. 807491.

Legault, L., Green-Demers, I., \& Pelletier, L. (2006). Why do high school students lack motivation in the classroom? Toward an understanding of academic amotivation and the role of social support. Journal of Educational Psychology, 98(3), 567-582. https://doi.org/10.1037/0022-0663.98.3.567.

Levy, D. A. (1992). The liberating effects of interpersonal influence - an empirical-investigation of disinhibitory contagion. Journal of Social Psychology, 132(4), 469-473. https://doi.org/10.1080/00224545.1992. 9924726.

Levy, D. A., \& Nail, P. R. (1993). Contagion: a theoretical and empirical review and reconceptualization. Genetic, Social, and General Psychology Monographs, 119(2), 233-284 Retrieved from https://www.ncbi. nlm.nih.gov/pubmed/8405969.

Li, Y. B., Lynch, A. D., Kalvin, C., Liu, J. J., \& Lerner, R. M. (2011). Peer relationships as a context for the development of school engagement during early adolescence. International Journal of Behavioral Development, 35(4), 329-342. https://doi.org/10.1177/0165025411402578.

Marsh, H. W., Hau, K.-T., \& Wen, Z. (2004). In search of golden rules: comment on hypothesis-testing approaches to setting cutoff values for fit indexes and dangers in overgeneralizing hu and bentler's (1999) findings. Structural Equation Modeling: A Multidisciplinary Journal, 11(3), 320-341. https://doi.org/10. 1207/s15328007sem11032.

Marsh, H. W., Hau, K.-T., \& Grayson, D. (2005). Goodness of fit in structural equation models. In Contemporary psychometrics: A festschrift for roderick p. Mcdonald (pp. 275-340). Mahwah, NJ, US: Lawrence Erlbaum associates publishers.

McGarty, C., Turner, J. C., Hogg, M. A., David, B., \& Wetherell, M. S. (1992). Group polarization as conformity to the prototypical group member. British Journal of Social Psychology, 31(1), 1-19. https://doi.org/10. 1111/j.2044-8309.1992.tb00952.x.

Mendoza, N. B., \& King, R. B. (2020). The social contagion of student engagement in school. School Psychology International, 41(5), 454 474. https://doi.org/10.1177/0143034320946803.

Meuleman, B., \& Billiet, J. (2009). A Monte Carlo sample size study: How many countries are needed for accurate multilevel SEM? Survey Research Methods, 3(1), 45-58. Retrieved from http://hdl.handle.net/ 1854/LU-1041001.

Muthén, L. K., \& Muthén, B. Q. (1998-2019). Mplus 8.3. Los Angeles, CA: Muthén \& Muthén. 
Nail, P. R., MacDonald, G., \& Levy, D. A. (2000). Proposal of a four-dimensional model of social response. Psychological Bulletin, 126(3), 454 470. https://doi.org/10.1037/0033-2909.126.3.454.

Nolen, S. B. (1988). Reasons for studying: motivational orientations and study strategies. Cognition and Instruction, 5(4), 269-287. https://doi.org/10.1207/s1532690xci0504_2.

OECD. (2019a). Pisa 2018 insights and interpretations. Retrieved from https://www.oecd.org/pisa/PISA\% 202018\%20Insights\%20and\%20Interpretations\%20FINAL\%20PDF.pdf. Accessed 21 Nov 2020.

OECD. (2019b). Results (volume i): What students know and can do. In. Paris: OECD Publishing.

Okabe, M. (2013). Where does Philippine education go? The "K to 12" program and reform of basic Philippine education. Chiba: Institute of Developing Economies (IDE).

Orleans, A. V. (2007). The condition of secondary school physics education in the Philippines: recent developments and remaining challenges for substantive improvements. Australian Educational Researcher, 34(1), 33-54. https://doi.org/10.1007/Bf03216849.

Persson, L., \& Svensson, M. (2017). Classmate characteristics, class composition and children's perceived classroom climate. Journal of Public Health, 25(5), 473-480. https://doi.org/10.1007/s10389-017-0809-0.

Pianta, R. C., Hamre, B. K., \& Allen, J. P. (2012). Teacher-student relationships and engagement: Conceptualizing, measuring, and improving the capacity of classroom interactions. In Handbook of research on student engagement (pp. 365-386). Berlin: Springer.

Radel, R., Sarrazin, P., Legrain, P., \& Wild, T. C. (2010). Social contagion of motivation between teacher and student: analyzing underlying processes. Journal of Educational Psychology, 102(3), 577-587. https://oi. org/10.1037/a0019051.

Seifert, T. L. (1997). Academic goals and emotions: results of a structural equation model and a cluster analysis. British Educational Research Journal, 67(( Pt 3)(3)), 323-338; discussion 339-343. https://doi.org/10.1111/ j.2044-8279.1997.tb01247.x.

Seifert, T. L., \& O'Keefe, B. A. (2001). The relationship of work avoidance and learning goals to perceived competence, externality and meaning. British Journal of Educational Psychology, 71(Pt 1), 81-92. https:// doi.org/10.1348/000709901158406.

Selig, J. P., \& Little, T. D. (2012). Autoregressive and cross-lagged panel analysis for longitudinal data. In Handbook of developmental research methods (pp. 265-278). New York, NY, US: The Guilford Press.

Simons-Morton, B., \& Chen, R. (2009). Peer and parent influences on school engagement among early adolescents. Youth Society, 41(1), 3-25. https://doi.org/10.1177/0044118X09334861.

Skaalvik, E. M. (1997). Self-enhancing and self-defeating ego orientation: relations with task and avoidance orientation, achievement, self-perceptions, and anxiety. Journal of Educational Psychology, 89(1), 71-81. https://doi.org/10.1037/0022-0663.89.1.71.

Skinner, E. A., Furrer, C. J., Marchand, G., \& Kindermann, T. A. (2008). Engagement and disaffection in the classroom: part of a larger motivational dynamic? Journal of Educational Psychology, 100(4), 765-781. https://doi.org/10.1037/a0012840.

Skinner, E. A., Kindermann, T. A., \& Furrer, C. J. (2009). A motivational perspective on engagement and disaffection. Educational and Psychological Measurement, 69(3), 493-525. https://doi.org/10.1177/ 0013164408323233.

Somuncuoglu, Y., \& Yildirim, A. (1999). Relationship between achievement goal orientations and use of learning strategies. Journal of Educational Research, 92(5), 267-277. https://doi.org/10.1080/ 00220679909597606.

Steiger, J. H. (1990). Structural model evaluation and modification: an interval estimation approach. Multivariate Behav Res, 25(2), 173-180. https://doi.org/10.1207/s15327906mbr2502_4.

Tanodra, E. Q. (2003). Philippine educational system. Quezon City, Philippines: Verh Educational Enterprise.

Urdan, T. (1997). Examining the relations among early adolescent students' goals and friends' orientation toward effort and achievement in school. Contemporary Educational Psychology, 22(2), 165-191. https://doi.org/ 10.1006/ceps.1997.0930.

Urdan, T. (2004). Predictors of academic self-handicapping and achievement: examining achievement goals, classroom goal structures, and culture. Journal of Educational Psychology, 96(2), 251-264. https://doi.org/ 10.1037/0022-0663.96.2.251.

Urdan, T., \& Schoenfelder, E. (2006). Classroom effects on student motivation: goal structures, social relationships, and competence beliefs. Journal of School Psychology, 44(5), 331-349. https://doi.org/10.1016/j.jsp. 2006.04 .003

Wang, M.-T., \& Fredricks, J. A. (2014). The reciprocal links between school engagement, youth problem behaviors, and school dropout during adolescence. Child Development, 85(2), 722-737. https://doi.org/10. 1111/cdev.12138.

Wang, M.-T., Fredricks, J., Ye, F., Hofkens, T., \& Linn, J. S. (2017). Conceptualization and assessment of adolescents' engagement and disengagement in school: a multidimensional school engagement scale. 
European Journal of Psychological Assessment, 35(4), 592-606. https://doi.org/10.1027/1015-5759/ a000431.

Wentzel, K. R., Muenks, K., McNeish, D., \& Russell, S. (2017). Peer and teacher supports in relation to motivation and effort: a multi-level study. Contemporary Educational Psychology, 49, 32-45. https:/doi. org/10.1016/j.cedpsych.2016.11.002.

Wild, T. C., \& Enzle, M. E. (2002). Social contagion of motivational orientations. In Handbook of selfdetermination research (pp. 141-157). Rochester, NY, US: University of Rochester Press.

Wild, B., Erb, M., \& Bartels, M. (2001). Are emotions contagious? Evoked emotions while viewing emotionally expressive faces: quality, quantity, time course and gender differences. Psychiatry Research, 102(2), 109124. https://doi.org/10.1016/S0165-1781(01)00225-6.

Publisher's note Springer Nature remains neutral with regard to jurisdictional claims in published maps and institutional affiliations.

Mr. Norman B. Mendoza. Department of Curriculum and Instruction, The Education University of Hong Kong, Ting Kok, Hong Kong

Current themes of research

Student engagement in school. Formative assessments. Achievement goals. Social contagion in the education context

Most relevant publications in the field of Psychology of Education

Mendoza, N. B., \& King, R. B. (2020). The social contagion of student engagement in school. School Psychology International, 41(5), 454 474. doi:https://doi.org/10.1177/0143034320946803

King, R.B. \& Mendoza, N.B. (2020). Achievement goal contagion: mastery and performance goals spread among classmates. Social Psychology of Education https://doi.org/10.1007/s11218-020-09559-x

Bernardo, A.B.I. \& Mendoza, N.B. (2020). Measuring hope during the COVID-19 outbreak in the Philippines: development and validation of the state locus-of-Hope scale short form in Filipino. Current Psychology https://doi.org/10.1007/s12144-020-00887-x

Dr. Ronnel B. King. Faculty of Education, University of Macau, Hengqin Island, Macau. ronnel.king@gmail.com

Current themes of research

Student motivation. Student well-being. Positive psychology and education.

\section{Most relevant publications in the field of Psychology of Education}

King, R. B. (2020). Mindsets are contagious: The social contagion of implicit theories of intelligence among classmates. British Journal of Educational Psychology, 90, 349-363.

King, R. B., \& Datu, J. A. D. (2017). Happy classes make happy students: Classmates' well-being predicts individual student well-being. Journal of School Psychology, 65, 116-128.

King, R.B., \& Datu, J. A. D. (2018). Grateful students are motivated, engaged, and successful: Cross-sectional, longitudinal, and experimental evidence. Journal of School Psychology, 70, 105-122.

King, R. B., \& McInerney, D. M. (2019). Family-support goals drive engagement and achievement in a collectivist context: Integrating etic and emic approaches in goal research. Contemporary Educational Psychology, 58, 338-353.

King, R. B., McInerney, D. M., \& Jain, R. (2018). Envisioning a culturally imaginative educational psychology. Educational Psychology Review, 30, 1031-1065. King, R.B. \& Mendoza, N.B. (2020). Achievement goal contagion: mastery and performance goals spread among classmates. Social Psychology of Education, 23, $795-814$ 